\title{
The Production of Chitosan from Shrimp Shell Waste and Its Formulation in Patch DosageForm Combined with Aloe vera Extract as Antiinfection Agent
}

\author{
Haeriah $^{1}$, Muhammad Rahmatullah $^{1}$, Andi Indardaya $^{1}$, Emilia Utomo $^{1}$, Novianti $^{2}$, Sartini $^{1}$ \\ ${ }^{1}$ Faculty of Pharmacy, Hasanuddin University, Indonesia \\ ${ }^{2}$ Faculty of Mathematics and Natural Sciences, Hasanuddin University, Indonesia
}

\begin{abstract}
Chitosan can be obtained from chitin isolated from shrimp waste through the process of deacetylation of chitin. Chitosan can be used as a patch base material because of its biocompatibility and biodegradability, and has antibacterial activity. The combination of Chitosan and Aloe vera extracts may be useful in patch dosage forms as wound dressings that have antiinfective activity. The aims of this research was to obtain patch from combination of Aloe vera $\mathrm{L}$. leaves extract and chitosan isolated from shrimp shell waste as antiinfection agent. Chitosan was obtained from shell waste sequentially by deproteinisation, demineralisation, and deacetylation processes, and analyzed its characteristic, respectively; Aloe vera gel was extracted using maceration methods with ethanol as solvent; patch was formulated using $2 \%$ chitosan in $1.5 \%$ glacial acetic acid, $1.6 \%$ Aloe vera extracts and $10 \%$ glycerin and evaluated its physical properties, skin iritation test, and antibacterial test against S.aureus. The results showed that patch made from the combination of shrimp waste chitosan and Aloe vera had good physical characteristics and effectively inhibit the growth of S.aureus. So, the combination of Aloe vera leaves extract and chitosan from shrimp shell as patch can be used as antiinfection wound healing.
\end{abstract}

\section{Article History}

Received 23 June 2017

Accepted 19 August 2017

Keyword

Aloe vera L.,

Chitosan,

wound dressing,

patch,

shrimp shell waste.

\section{Introduction}

The injury in which skin is torn, cut or punctured, also called wound (Katari et al.,2014; Varshney \& Dhyani, 2015). Wound healing is the process comprising of healing of dermal and epidermal tissues by their regeneration (Katari et al., 2014; Takeo et al., 2015). It involves consecutive cascade of stages inflammation, migration, proliferation, and maturation (Katari et al., 2014; Takeo et al., 2015). Skin itself repairs the wound but open wounds faces a number of anomalies like infection (sepsis) from 19 air, water pollutants and microorganisms, its spread to health tissues and tissue disruption (rupture) and even to others (Katari et al., 2014; Devika \& Koilpillai, 2014). Staphylococcus aureus is one of the most common bacteria caused infection (Choudury et al., 2012; Rajan et al., 2016). Previous research showed that this type 
of bacteria caused mild skin infections and postoperative wounds since 1880s (Choudury et al., 2012; Vijayalakshmi, 2015).

One of the most popular local drug delivery system today is transdermal drug delivery system in the form of transdermal patch (Fathima et al., 2017; Sachan \& Bajpai, 2013). It is preferred because it has many advantages compared to other preparations (e.g. oral dosage form) (Fathima et al., 2017; Sachan \& Bajpai, 2013). One of the polymers used in transdermal patch formulation is chitosan (Fathima et al., 2017; Daniel \& Hamblin, 2016). Chitosan is used as the part of drug delivery system because of its biocompatibility and biodegradability (Fathima et al., 2017; Daniel \& Hamblin, 2016).

Chitosan can be obtained from chitin that is isolated from shrimp shell waste by chitin deacetylation (Alami \& Permatasari, 2016; Ahing \& Wid, 2016). Chitin content on shrimp shell waste is about 15-20\% of dry weight (Alami \& Permatasari, 2016; Danujatmiko et al., 2014). Shrimp waste is its head and shell that cause environmental pollution (Alami \& Permatasari, 2016; Ahing \& Wid, 2016). Therefore, this waste can be utilized as chitosan source (Alami \& Permatasari, 2016; Ahing \& Wid, 2016). Based on Bellamkonda et al. (2017) showed that the obtained chitosan has antibacterial activity against Staphylococcus aureus (Bellamkonda et al., 2017). Hence, chitosan in patch preparation has two functions, as polymer in patch formulation and as antibacterial agent.

One of the natural materials that has been known to be used in wound healing is Aloe vera L. (Silva et al., 2013; Sharma et al., 2015). Aloe vera L. has an activity as antibacterial, as evidenced by the results of a study conducted by Jothi et al. (2014) showing that Aloe vera can inhibit the growth of Staphylococcus aureus bacteria with a percentage of resistance of 61-66\% (Jothi et al., 2014). Aside from being an antibacterial, Aloe vera L. also has increased collagen content within the wound, supporting faster wound healing (Silva et al., 2013; Sharma et al., 2015). Aloe vera contains many active substances that are essential for wound healing (Silva et al., 2013; Mahor et al., 2016). Based on the results of research conducted by Tudose et al. (2009) on NCTC2544 cells showed that cells given Aloe vera extract experienced higher cell proliferation than control (Tudose et al., 2009). These results suggest that Aloe vera can be used as a topical natural treatment (Tudose et al., 2009; Mahor, 2016). Both activities possessed by Aloe vera are very useful in wound healing due to its synergistic effect in this research. This study aims to obtain patch from Aloe vera extract combination and chitosan as wound dressing.

\section{Materials and Methods}

\section{Isolation of Chitosan}

Shrimp shell was obtained from Kima industry in Makassar. The waste was then washed and cleaned using running water, and mashed using blender. Next, the dried waste was kept in closed container.

\section{Isolation of Chitin}

The process of chitin isolation involved two steps. Firstly, demineralization which was done by soaking the dried waste in 2 liters of $3 \%$ hydrochloric acid for 16 hours at room temperature. After that, the residue was washed and soaked in distilled water until netral. Secondly, deproteinization which was done by soaking the residue in 2 liters of $4 \%$ sodium hydroxide solution for 20 hours at room temperature. 


\section{Purification of Chitosan (Deacetylation)}

The residue was washed and soaked in distilled water until netral then dried. Deacetylation process was done by soaking the residue in 2 litres of $60 \%$ sodium hydroxide solution for 20 hours at $65^{\circ} \mathrm{C}$. Afterwards, it was washed using distilled water until netral. The obtained residue was chitosan which was then dried for 4 hours at $65 \pm 5^{\circ} \mathrm{C}$ and ready to characterize.

\section{Analysis of Chitosan}

Chitosan analysis consists of pharmaceutical and chemistry analysis. The pharmaceuticals analysis includes $\mathrm{pH}$ measurement of chitosan solution using $\mathrm{pH}$ meter, viscosity measurement of chitosan solution Brookfield ${ }^{\circledR}$ viscometer, solubility test which was done by dissolving $0.5 \mathrm{~g}$ of chitosan with $50 \mathrm{ml}$ of $1 \%$ acetic acid, stirring for $30 \mathrm{~min}$ and observed solubility, and morphology observation using Scanning Electron Microscopy. The chemistry analysis includes crystallinity detection using X-Ray Diffraction Spectrometer, functional groups observation using infrared spectroscopy in $4000-400 \mathrm{~cm}^{-1}$, and degree of deacetylation calculation based on FT-IR results, using the following formula:

$$
D D A(\%)=\left[\left(1-\left(\frac{\mathrm{A} 1655}{\mathrm{~A} 3450} \times \frac{1}{1,33}\right)\right) \times 100\right]
$$

\section{Extraction of Aloe vera}

Aloe vera leaves was washed using distilled water to remove the dirts and then peeled. The gel of Aloe vera was cut into small pieces and then mashed. After that, it was dried in the oven for 24 hours at $80^{\circ} \mathrm{C}$. The dried gel was macerated using ethanol $96 \%$ for 24 hours. The solvent was evaporated using rotary evaporator to obtain the viscous extract.

\section{Analysis of Aloe vera Extract Antibacterial Test}

Antibacterial test was done by using agar diffusion method. A total of $30 \mathrm{mg}$ of extract were dissolved in $3 \mathrm{ml}$ of DMSO. Ten microlitres of Staphylococcus aureusculture suspension was added into petri dish followed by $15 \mathrm{ml}$ of MHA media. A total of $40 \mu \mathrm{l}$ and $80 \mu \mathrm{l}$ of extract solution was added into paper disc which was placed on the agar surface. It was incubated for $1 \times 24$ hours at $37^{\circ} \mathrm{C}$. The formed inhibit zone was then observed.

\section{Qualitative Test of Acemannan in Aloe vera Extract}

A total of $100 \mathrm{mg}$ extract was added to $1 \mathrm{ml}$ of distilled water. After that, $2.5 \mathrm{ml}$ of 0.2 $\mathrm{M}$ sodium hydroxide solution and $1 \mathrm{ml}$ of $0.0002 \mathrm{M}$ congo red solution were added consecutively. The formed color was observed.

\section{Formulation of Patch}

Two percents of chitosan was dissolved in $1.5 \%(\mathrm{v} / \mathrm{v})$ glacial acetic acid. Afterwards, $10 \%$ of glycerin and $1.6 \%$ of Aloe vera extract were added consecutively while stirring. About $20 \mathrm{~g}$ of the solution was poured into petri dish and then dried in the oven for 48 hours at $40^{\circ} \mathrm{C}$.

\section{Evaluation of Patch}

The thickness of the patch was measured using vernier calipers at 3 different points. The folding endurance of patch was measured manually by cutting the patch by $1 \mathrm{~cm}^{2}$ and 
folded repeatedly in the same place till broken. The number of folds without fracture was the value of folding ability. Patch was weighed and placed in container containing $100 \mathrm{ml}$ saturated solution of potassium chloride. After 24 hours, patch then weighed again. The percentage of moisture uptake was measured using the following formula:

$$
\% \text { moisture absorption }=\frac{\text { final weight }- \text { Initial weight }}{\text { Initial weight }} \times 100
$$

\section{Moisture Content Measurement}

Patch was weighed accurately and placed in container containing silica gel. After 24 hours, patch then weighed again. The percentage of moisture loss was calculated using the formula below:

$$
\% \text { moisture loss }=\frac{\text { Initial weight }- \text { Final weight }}{\text { Final weight }} \times 100
$$

\section{Skin Irritation Test}

The test used three rats (Rattus novergicus) as test animals. The patch was pasted on the back of the rat (Rattus novergicus) for 24 hours. Erithema and edema were observed after 24 hours treatment.

\section{Antibacterial Test}

Antibacterial test was conducted using Staphylococcus aureus culture in Mueller Hilton Agar media and tetracycline as a positive control. $0.1 \mathrm{ml}$ of bacteria suspension was added in petri dish followed by MHA media. Circle shaped patch with diameter $5.5 \mathrm{~mm}$ was placed on the surface of the media. Twenty microliters of $30 \mathrm{ppm}$ tetracycline solution in paper disk was also placed on the surface of medium. It was then incubated for $1 \times 24$ hours at $37^{\circ} \mathrm{C}$. The formed inhibitory zone was observed.

\section{Results and discussion}

\section{Isolation and Characterization of Chitosan from Shrimp Shell Waste}

The percentage of yield of chitosan that obtained was $32.67 \%$. In addition, there are also $8 \%-10 \%$ of calcium phosphate of total anorganic substances. Deproteinization purpose is to break the bond between protein and chitins, by adding sodium hydroxide. In its extracted crude form, chitin has a highly ordered crystalline structure, is translucent, resilient and quite tough. It has, however, poor solubility and low reactivity (Abbaas, 2015). Deacetylation aims to remove the acetyl group that attach in chitin. In deacetylation process, high concentration of sodium hydroxide solution $(40-60 \%)$ is used to obtained chitosan from chitin. Chitosan characterization results is presented in Table 1.

Table 1. Characterization of Chitosan Isolated from Shrimp Shell Waste

\begin{tabular}{|c|c|}
\hline Analysis & Result \\
\hline $\mathrm{pH}$ & 4 \\
\hline Solubility in glacial acetic acid & Soluble in $1 \%$ solution \\
\hline Viscosity & $93.33 \mathrm{cps}$ \\
\hline
\end{tabular}


In table $1, \mathrm{pH}$ of chitosan was 4 , while the previous studies got 8.5. In the extraction process, strong acid (hydrochloric acid) and strong base (sodium hydroxide) were used, so that different volume or concentration that used can affect the $\mathrm{pH}$ of chitosan. The solubility of chitosan in glacial acetic acid was one of the parameters that can be used as standard of chitosan quality. The highest the solubility, the better chitosan obtained. In this test, the solubility of chitosan sample and chitosan standard was the same that 1 gram of chitosan dissolved in $100 \mathrm{ml}$ of glacial acetic acid. The measurement of viscosity gave the result of $93.33 \mathrm{cps}$ of chitosan sample and $86.67 \mathrm{cps}$ of chitosan standard.

The result of chitosan characterization using FT-IR spectroscopy was given in Figure 1 which was chitosan sample and chitosan standard, respectively. In the analysis using FT-IR, it can be clearly seen that peak area of chitosan sample was in the range of 3724.54-349.12 $\mathrm{nm}^{-1}$, while the peak area of chitosan standard was in the range of $3722.61-352.97 \mathrm{~nm}^{-1}$. For the deacetylation degree calculation is obtained $30 \%$ and $37.7 \%$ for chitosan sample and chitosan standard, respectively. It indicated that there is no significant characteristic differences between sample and standard.
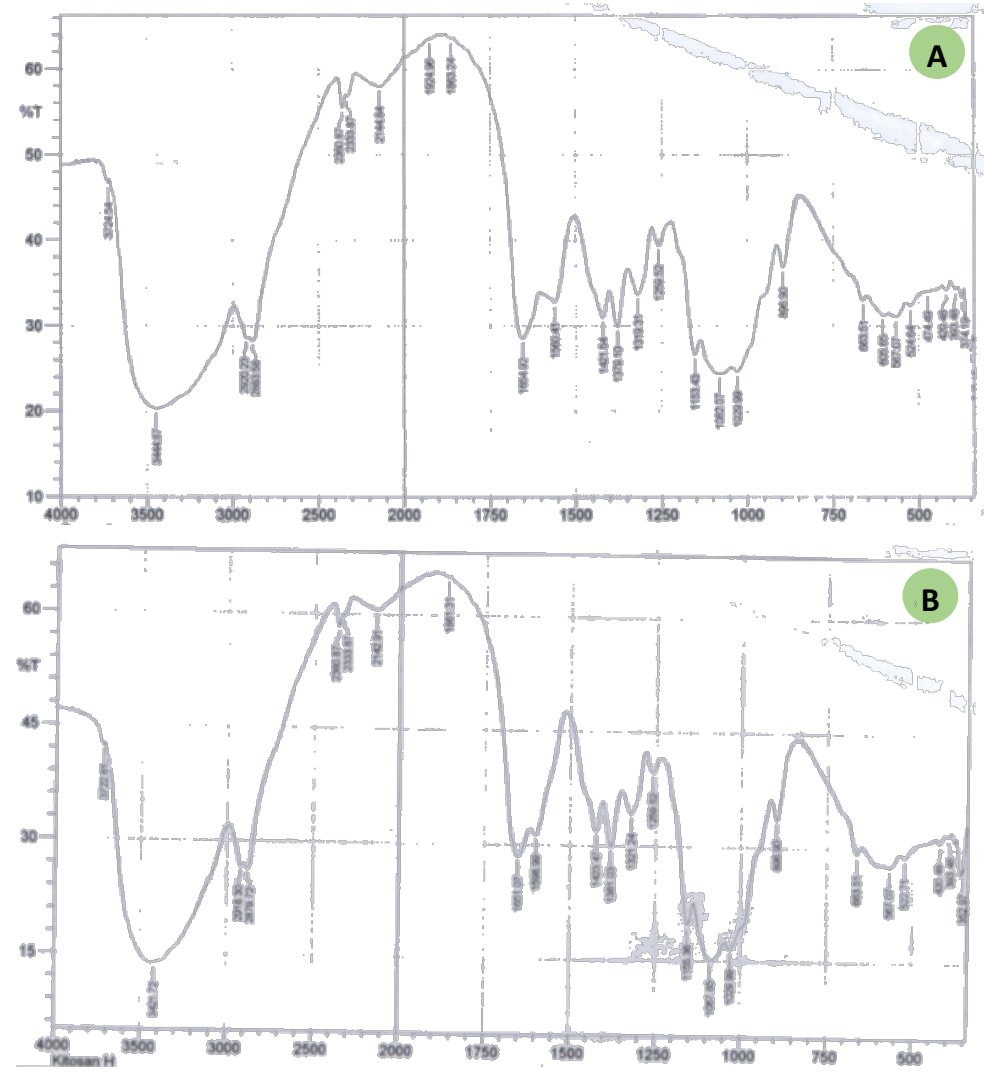

Figure 1. FT-IR Spectra of Chitosan

(A. Chitosan Sample, B. Chitosan Standard)

In the analysis using XRD, theoretically said that the crystal of chitin will be decreased after changed to chitosan, which the strongest reflection index was at the $9-10$ degrees because in that area there was an incorporation of water molecules into crystal lattices. Crystallinity degree is depend on deacetylation degree of chitosan; the higher the degree of deacetylation, the higher the degree of crystallinity (Yuan et al., 2011). This may be caused by the fact that chitosan chain with higher deacetylation cause the particles become more 
flexible and have less acetyl groups. The results of this analysis is presented in Table 2 and Figure 2.
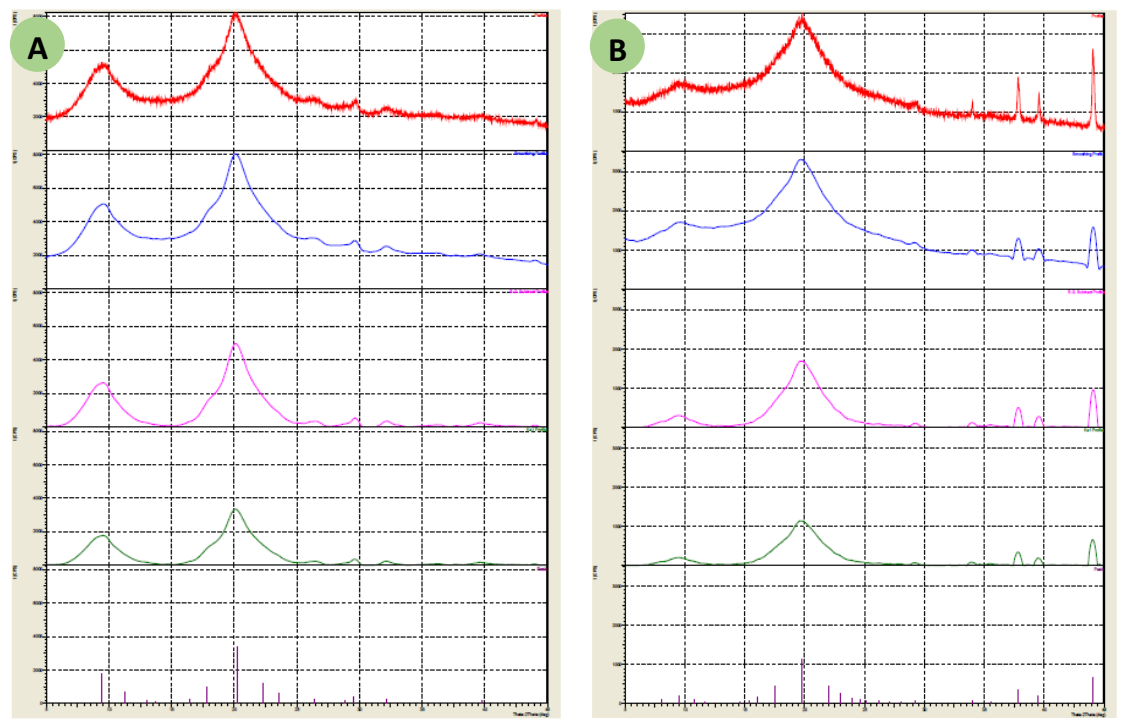

Figure 2. X-Ray Diffraction Results

(A. Chitosan Sample, B. Chitosan Standard)

Table 2. CrI Value of Chitosan Standard and Chitosan Sample

\begin{tabular}{|l|l|l|}
\hline \multirow{2}{*}{ Types of Chitosan } & \multicolumn{2}{|c|}{ CrI } \\
\cline { 2 - 3 } & $\mathbf{C r I}_{110}$ & $\mathbf{C r l}_{\mathbf{0 2 0}}$ \\
\hline Chitosan Standard & 18.5144 & -101.25 \\
\hline Chitosan Sample & 18.7048 & -75.20 \\
\hline
\end{tabular}

Observation of chitosan structure using scanning electron microscopy (SEM), theoretically said that chitosan has smooth morphology with minimum residue, while according to research that is conducted by Islam et al. (2011), reported that chitosan was not homogen and has a bit not smooth surface with the presence of bond and shrinkage on the surface. Based on that information, the result that obtained were appropriate (Figure 3).
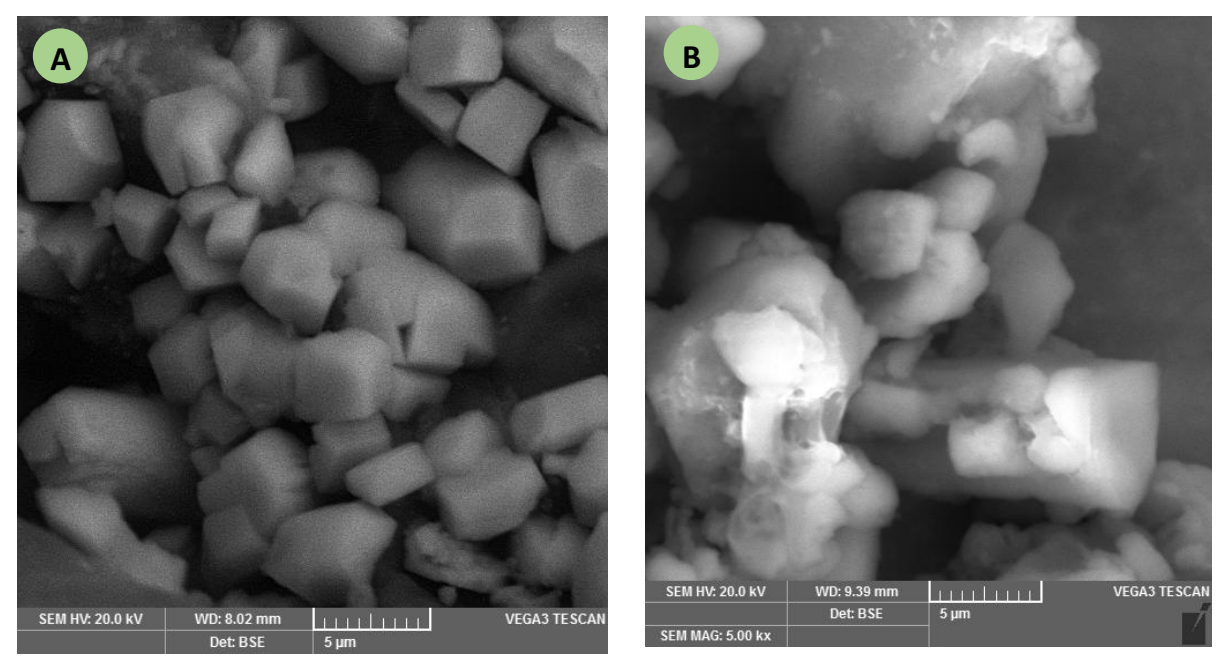

Figure 3. Morphology Observation Results Using SEM

(A. Chitosan Sample, B. Chitosan Standard) 


\section{Extraction of Aloe vera Leaves}

The results of Aloe vera leaves extraction was obtained the percentage of yield of $22.73 \%$. The qualitative test of acemannan in Aloe vera extract gave positive result which was showed by red complex formed after the addition of congo red in an alkaline situation. This positive result indicated that Aloe vera extract contained acemannan as cell regeneration stimulating agent. Acemannan is a linear polysaccharide composed by $(1,4)$-linked mannosyl residues, with $\mathrm{C} 2$ or $\mathrm{C} 3$ acetylated and some side-chains formed by galactose units attached to $\mathrm{C6}$. It is a $\beta-(1,4)$--linkedpolydispersed, highly acetylated mannan with an average molecular weight of approximately $1000 \mathrm{kDa}$, is obtained from the inner leaf of Aloe vera. Acemannan has shown to accelerate wound healing. Acemannan produces immune agents such as interferon and interleukin which help to destroy viruses, bacteria, and tumor (cancer) cells (Coche et al., 2014). The result of antibacterial activity test is shown in Table 3.

Table 3. Average Diameter of Inhibitory Zone of Aloe vera Extract ( $\mathrm{mm})$

\begin{tabular}{|c|c|c|c|}
\hline \multirow{2}{*}{ Concentration of Extract } & \multicolumn{2}{|l|}{$\begin{array}{l}\text { Diameter of Inhibitory } \\
\text { Zone }\end{array}$} & \multirow{2}{*}{ Average Diameter } \\
\cline { 2 - 3 } & 1 & 2 & \\
\hline $80 \mu \mathrm{l}(1.6 \%)$ & 7.78 & 8.84 & 8.31 \\
\hline $40 \mu \mathrm{l}(0.8 \%)$ & 0 & 0 & 0 \\
\hline
\end{tabular}

\section{Formulation and Evaluation of Transdermal Patch}

The obtained chitosan and Aloe vera extract were then formulated in transdermal patch which evaluation results is shown in Table 4.

Table 4. Evaluation Results of Transdermal Patch

\begin{tabular}{|l|l|}
\hline \multicolumn{1}{|c|}{ Tests } & Results \\
\hline Moisture Uptake Test (\%) & 40.03 \\
\hline Moisture Content Test (\%) & 23.64 \\
\hline Thickness Test (mm) & 0.45 \\
\hline Folding Endurance Test (times) & 114 \\
\hline Skin Irritation Test & Not irritating \\
\hline
\end{tabular}

Prepared tansdermal patch showed good physical characteristic. As in study by Jaydatt \& Sreenivas (2013) showed that transdermal patch have good physical characteristic with thickness varies between 0.42-0.45 mm, folding endurance between 102-137 times (Jaydatt \& Sreenivas, 2013) while the higher percentage of moisture uptake and moisture content is due to its hydrophobic nature of the polymer used (Kumar et al., 2012).

The antibacterial activity test was done using positive control (tetracyline) in order to compare the activity of patch with tetracycline. Tetracycline is one of antibiotic which is commonly used to treat infection caused by $S$. aureus. The result of antibacterial activity test showed that transdermal patch of chitosan and Aloe vera extract has antibacterial effect against Staphylococcus aureus with the average diameter of inhibitory zone of 6.39. The diameter of inhibitory zone of positive control (tetracycline) was $7.73 \mathrm{~mm}$ which was not significantly different from the patch. This indicated that the ability of Aloe vera extract and chitosan to inhibit the growth of $S$. aureus was not much different with tetracyline. Arunkumar \& Mutuselyam (2009) showed that ethanol extract from Aloe vera can inhibit $S$. Aureus (Arunkumar \& Mutuselyam, 2009), and Morshed et al. (2011) showed chitosan 
isolated from shrimp shells having activity against $S$. aureus bacteria with a $10 \mathrm{~mm}$ inhibit zone (Morshed et al., 2011).

The description of results above are supported by several studies, including: Rahman et al. (2017), which said that Aloe vera has a cell regeneration effect of acemannan compounds and the antibacterial effects of aloin compounds (Rahman et al., 2017). Another study, Hong et al. (2017), said that chitosan is a polymer that is often used in topical preparations because of its highly beneficial mucoadhesive properties against drug delivery to mucoid-covered organ targets (Hong et al., 2017). In addition, it has the effect of wound healing as well as antibacterial.

Research has shown that Aloe vera increases the collagen content and promotes faster wound healing. In addition, chitosan has been widely used as a base material in matrix production for wound management because of its easy production, long shelf life and the intrinsic nature of this polymer (Silva et al., 2013). Therefore, it can be said that the results of this research has been in accordance with existing theories and supported by some previous research.

\section{Conclusion}

Combination of chitosan form shimp shell waste and Aloe vera extract can be formulated into patch dosageform which had antibacterial activity against Staphylococcus aureus.

\section{Acknowledgements}

This research was supported by Ditjen Belmawa Kemenristekdikti (Ministry of Research, Technology, and Higher Education) for Research Grant 2017. The authors would like to thank the supervisor as well as the parties who have helped the authors in completing this research.

\section{References}

Abbaas.A.A.F. 2015. Dynamic Assessment of Biocidal Properties of Silicon-ChitosanContaining Hydrogels. International Journal of Innovative Research in Science, Engineering and Technology. 4(4): 2045-2050.

Ahing,F.A., \& N, Wid. 2016. Extraction and Characterization of Chitosan from Shrimp Shell Waste in Sabah. Transactions on Science and Technology. 3(1-2): 227-237.

Alami, R. \& Permatasari, L. 2016. Industry Pharmaceuticals : Chitosan as an Alternative Replacement Gelatin Capsules on Shell. Journal of Medical and Bioengineering.5(1):6771.

Arunkumar, S. \& Muthuselvam, M. 2009. Analysis of Phytochemical Constituents and Antimicrobial Activities of Aloe vera L. Against Clinical Pathogens. World Journal of Agricultural Sciences.5(5):572-576.

Bellamkonda, V., Vidya, S.R.G., \& Vijaya, C. 2017. Chitosan from Shrimp Bio-Waste: Potential Antibacterial Agent. International Journal of Informative \& Futuristic Research. 4(5):6398-6403.

Coche, T., Shende A., \& Kadu, P. 2014. Extraction and Identification of Bioactive Components from Aloe barbadensis Miller. Journal of Pharmacognsoy and Phytochemistry. 2(1):1423. 
Choudhury, R., Sasmita, P., Savitri, S., \& Durg, V.S 2012. Staphylococcal Infection, Antibiotic Resistance and Therapeutics. Intech. 247-272.

Daniel, E.A.K., \& M.R, Hamblin. Chitin and Chitosan: Production and Application of Versatile Biomedical Nanomaterials. NCBI Journal. 4(3): 411-427.

Danujatmiko, Z., O.L, Ki., Aylianawati., \& Y, Sudaryanto. 2014. The Prospect of Shrimp Shell Waste as Raw Material in Gelatin Production. ARPN Journal of Engineering and Applied Sciences. 9(11): 2035-2038.

Devika, R., \& J, Koilpillai. 2014. Etiology of Wound Healing and Hypertrophic Scar Formation. International Journal of Pharmaceutical Science and Health Care. 3(4): 78-86.

Fathima, S.A., Begum, S., \& Syeda, S.F. 2017. Transdermal Drug Delivery System. International Journal of Pharmaceutical and Clinical Research.9(1):35-43.

Hong, S., S.Y, Yoo., H, Kim., \& J, Lee. 2014. Chitosan-Based Multifunctional Platforms for Local Delivery of Therapeutics. Marine Drugs Journal.15(60):1-6.

Jaydatt, J., \& Sreenivas, S.A. 2012. Formulation \& In Vitro Polymer Evaluation of Drug Reservoir Transdermal Patches of Piroxicam Using Polymers HPMC E15, PVP K30 \& Eudragit L100. International Journal of Pharmaceutical Innovations. 3(5): 67-80.

Kataria, K., Gupta, A., Rath, G., Mathur., \& Dhakate. 2014. In vivo Wound Healing Performance of Drug Loaded Electrospun Composite Nanofibers Transdermal Patch. International Journal of Pharmaceutics ELSVIER. 1-9.

Kumar, S.R., Jain, A., \& Nayak, S. 2012. Development and Evaluation of Transdermal Patches of Colchicine. Scholars Research Library. 4(1): 330-343.

Li, Q., Dunn, E.T., \& Grandmaison, E.W. 1997. Applications and Properties of Chitosan, in: M.F.A. Goosen (Ed.) Applications of Chitin and Chitosan. Technomic Publishing Co. Lancaster.

Mahor, G., \& S.A, Ali. 2016. Recent Update on The Medicinal Properties and Use of Aloe vera in The Treatment of Various Ailments.Bioscience Biotechnology Research Communications. 9(2): 273-288.

Morshed, M.A., A.A, Bashir., M.H, Khan., \& M.K, Alam. 2011. Antibacterial activity of Shrimp Chitosan Against Some Local Food Spoilage Bacteria and Food Borne Pathogens. Bangladesh J Microbiol. 29(1): 45-47.

Rahman, S., P.Carter., \& N, Bhattarai. 2017. Aloe vera for Tissue Enggineering Applications. Journal of Infectional Bimaterials. 8(6):1-17.

Rajan, P.A., Christoper, D.T., M.J, Aman., \& Jean, C.L. 2016. Protective Efficacy of A Novel Alpha Hemolysin Subunit Vaccine (AT62) Against Staphylococcus aureus Skin and Soft Tissue Infections. Vaccine, ELSEVIER: 1-6.

Sachan, R., \& M, Bajpai. 2013. Transdermal Drug Delivery System: A Review. International Journal Research Development Pharmacy. 3(1): 748-765.

Sharma, K., Ashul, M., \& Nitesh, C. 2015. Aloe vera ad Penetration Enhancer. International Journal Drug Delivery and Research. 7(1): 31-34.

Silva., E.G, Popa., M.E, Gomes., M, Cerqueira., A.P, Marques., S.G, Caridade., P, Teixeira., C, Sousa., J.F, Mano., \& R.L, Reis. 2013. An Investigation of The Potential Application of Chitosan/Aloe-based Membranes for Regenerative Medicine. Acta Biomaterialia ELSEVIER. 9:6790-6797.

Takeo, M., Wendy, L., \& Mayumi, I. 2015.Wound Healing and Skin Regeneration. Cold Spring Habor Perspective in Medicine.5: 1-12. 
Tudose, A., Christian, C., Francesco, C., Margherita, V., Roberto, M., \& Donatella, P. 2009. Regenerative Properties of Aloe vera Juice on Human Keratinocyte Cell Culture. Farmacia. 57:590-596.

Varshney, S., \& S, Dhyani. 2015. Medicinal Herbs Having Incredible Wound Healing Effects. International Journal of Research. 6(5): 573-579.

Vijayalakshmi, P. 2015. Incidence of Staphylococcus aureus in Surgical Site Infections in A Teaching Hospital. 4(4): 32-34.

Yuan, Y., Betsy, M.C., Warren, O.H., \& Joel, D.B. 2011. Deacetylation of Chitosan:Material Characterization and In Vitro Evaluation via Albumin Adsorption and Pre-Osteoblastic Cell Cultures

\section{To cite this article:}

Haeriah, Rahmatullah, M., Indardaya, A., Utomo' E., Novianti \& Sartini. 2017. The Production of Chitosan from Shrimp Shell Waste and Its Formulation in Patch DosageForm Combined with Aloe vera Extract as Antiinfection Agent. International Journal of Applied Biology. 1(1) : 22-31. 